EVIDENCE BASED PUBLIC HEALTH POLICY AND PRACTICE

\title{
Putting public health evidence into practice: increasing the prevalence of working smoke alarms in disadvantaged inner city housing
}

\author{
H Roberts, K Curtis, K Liabo, D Rowland, C DiGuiseppi, I Roberts
}

J Epidemiol Community Health 2004;58:280-285. doi: 10.1136/jech.2003.007948

See end of article for authors' affiliations

Correspondence to:

Ms K Curtis, Child Health Research and Policy Unit, Institute of Health Sciences, City University, 20 Bartholomew Close London ECIA 7QN, UK; k.curtis@city.ac.uk

Accepted for publication 30 June 2003

\begin{abstract}
Study objectives: The UK government recommends that local authorities install battery operated smoke alarms to prevent fire related injury. However, a randomised controlled trial of smoke alarm installation in local authority housing found a low level of working alarms at follow up. Qualitative work, which accompanied the trial explored barriers and levers to the use of this public health intervention.

Design: Semi-structured group and individual interviews were conducted with a sample of the adult participants in a randomised controlled trial of free smoke alarm installation. Group interviews and "draw and write" exercises were conducted with children at a local primary school.

Participants: A sample of trial participants and primary school children in the trial neighbourhood.

Setting: An inner city housing estate in central London.

Main results: The main barrier to smoke alarm use was the distress caused by false alarms. Although trial participants considered themselves to be at high risk for fires and would recommend smoke alarms to others, respondents' reports on the distress caused by false alarms suggest that people balance immediate and longer term risks to their health and wellbeing when they disable alarms.

Conclusions: This study identified some of the reasons for the low level of functioning smoke alarms, and problems experienced with alarms. The results have implications for the implementation of this public health intervention. The effectiveness of smoke alarm installation could be improved if alarm manufacturers and those responsible for implementation programmes considered ways of tackling the issues raised in this study.
\end{abstract}

the trial results suggested that this should lead us to consider the difference between an efficacy trial (what works in perfect conditions) and an effectiveness trial (what works in the real world). ${ }^{7}$

Public health interventions, like clinical ones, can have both beneficial and adverse effects, and those on the receiving end can provide important insights into why some interventions may be less effective than anticipated. ${ }^{89}$

Rychetnick et al point out that interpretation of the evidence in public health depends on the availability of a range of types of data, and that the appraisal of evidence about public health interventions should encompass not only the credibility of evidence, but also its completeness and its transferability. ${ }^{10}$ By focusing on some of the non-trial data from a particular intervention, this paper adds to the literature on the kinds of evidence needed to promote the use of research findings in "real life" settings.

This paper reports the results of a qualitative study carried out with participants in the randomised controlled trial of smoke alarms, ${ }^{5}$ and children in the trial neighbourhood. It identifies barriers to the continued use of smoke alarms, and illustrates how qualitative work can inform the design of randomised controlled trials of preventive interventions and provide information for policy at local and national levels.

\section{METHODS}

This study was conducted on a local authority housing estate in London between November 1999 and March 2002. The estate is materially deprived and $23 \%$ of residents speak primary languages other than English. The location was selected as one likely to reflect features associated with a high risk of house fires-that is, low income areas, deprived council estates, and housing in poor physical condition. ${ }^{11}$ functional, meaning that nearly half became non-functional after 15 months. An editorial accompanying publication of 
There is a steep social class gradient in the likelihood of fire related mortality and morbidity. ${ }^{12}{ }^{13}$

Purposive samples were derived for the qualitative work. ${ }^{14}$ Using data collected from participants at trial enrolment, we identified households across a range of ethnicities, ages, disability, household formations, housing types, housing tenure, and incorporating all five alarm types used in the trial, as well as households that had been randomised but ultimately refused or otherwise did not receive the intervention (6.6\% of trial sample). Recruitment ensured that people with infants under 4 years and people aged over 65 were sampled. On the basis of resources available, contact was planned with around 50 adults and 50 children through group and one to one approaches. Our analyses suggest that data saturation was reached with these numbers. ${ }^{15}$ Discussions were also held with trial recruiters and alarm installers to gather information on reasons for refusing participation in the trial.

Adult occupants of identified households taking part in the trial who had supplied a telephone number $(88 \%$ of all participants) were telephoned to invite them to take part in the qualitative work, and a follow up confirmation letter sent. Group interviews took place in a local community centre. Evening interviews were held for those at work during the day. If people were unable to leave the house, we offered to meet them at home. Those contacted who were not fluent in English were asked whether they would like an interpreter. Children, aged 7-11, from the local primary school were also invited to take part and the interviews took place in class groups in the school. We used an opt out approach to parental consent. Children's own consent was also sought.

We collected data using a range of qualitative methods. These included individual and group interviews with adults, and group interviews, questionnaires and "draw and write" techniques with children. Questions were based around a topic guide, with follow up prompts. Critical incidents were explored in more depth with interviewees. These included two cases where alarms would not stop; one of a fire in a next door flat; one where the participant smashed her alarm; one where the participant felt suspicious of staff who introduced the project; and one where a participant had a fire at home and was alerted by the alarm.

The topic guide included perceptions of fire risk, benefits and problems of living with a smoke alarm, and reflections on participation in a trial. We asked whether having a smoke alarm would influence the decision to recommend alarms to others. To avoid compromising the dynamics of the groups by introducing what might be seen as a matter of right or wrong, we did not ask participants to indicate whether their alarm was currently functioning. Finally, there was an opportunity for feedback on topics of importance to participants that we had not covered. Children were invited to talk with us about a similar range of topics, and were given a "work book" to complete, which encouraged drawings and written responses. We wanted to know whether they recognised smoke alarms, whether they knew how they were supposed to operate, and what happened if they went off (or on, as one child corrected us).

Gender was recorded by the researchers facilitating the session. We asked adult participants to describe themselves in terms of age and ethnicity. We met with whole classes of children, so the ethnic make up is likely to be representative of their year group. Work conducted in 1997 among children at this primary school, as part of a larger survey, ${ }^{16}$ indicated that $69 \%$ were Asian (63\% Bangladeshi), 16\% white, 5\% black, and $10 \%$ other/unknown.

Two researchers facilitated all group sessions. For individual interviews with housebound participants, and those who did not speak English (for whom we used interpreters), interviews took place in the participant's home, with one researcher. Telephone interviews were carried out with those who had been randomised but did not receive the intervention. All interviews were recorded and transcribed. Researchers read the data independently for key themes, and differences in interpretation were resolved through discussion. In this particular study, where the themes and issues raised were comparatively straightforward, simple discussion between the primary fieldworkers ( $\mathrm{KC}$ and $\mathrm{KL}$ ) and HR was sufficient to resolve differences.

The Institute of Child Health Research Ethics Committee approved the study protocol.

\section{RESULTS}

Over the one year study period, we interviewed a total of 58 adults. Ten group interviews involved a total of 39 participants with group sizes ranging from three to nine people and we conducted nine individual interviews, three with housebound participants and six with non-English speakers. We interviewed 10 people who had been randomised to the intervention but had not received it. Table 1 shows self identified ages, ethnicities, and other characteristics. About one in five adults agreed to take part in the study when initially approached, and about half of those who expressed initial interest attended discussion groups or agreed to a home interview. Four group interviews were conducted with a total of 41 children. Detailed results from the child participants will be reported elsewhere.

Based on trial data, $63 \%$ of participants in the qualitative study had a working smoke alarm at the end of the 15 month trial. Levers to continued alarm use included early warning in the event of fire, and as a result, an increased sense of security. Those who refused installation of an alarm said that they already had one (in two cases participants revealed at follow up that this was not yet installed), expressed concern at receiving an intervention that entailed a stranger coming into their home, or were suspicious of an intervention provided free. Some potential participants perceived themselves to be "too old to be worth spending money on."

Among those who accepted an alarm, there was a sense of being at high risk for fire. The intervention should, they felt, be recommended to others. However, they identified a range of barriers to continuing use after installation. These cast light on the low level of alarm functioning at follow up.

\section{Alarms as a source of stress}

Participants described important adverse effects of smoke alarms including the stress of false alarms:

It is an incredible noise and I don't get panicked ... but when that came on I was just like 'Oh!' It's such a pitch you just really want to stop it, and in your own home. It's a really calm safe environment and suddenly you've got this, you know, it's screaming at you... you feel completely powerless and that's a horrible feeling in your home, it's something you can't control.

Mother, white (1)*

It only went off once, when I burnt something in the kitchen. By that time it had been up for about 8 months. I have a very high ceiling in the hallway and I'd forgotten how to turn it off. I have a three-year-old daughter, it

*Overall ages, ethnicities, and other characteristics are provided in table 1. We asked those we interviewed to describe themselves, and some declined to provide age or ethnicity data. For this reason, not all respondents are described in the same way. 
Table 1 Participants in the study

\begin{tabular}{|c|c|c|c|c|c|c|c|c|c|c|c|c|c|c|c|}
\hline & \multirow[b]{2}{*}{ Number } & \multirow[b]{2}{*}{$\begin{array}{l}\text { Number } \\
\text { of groups }\end{array}$} & \multicolumn{3}{|c|}{ Gender } & \multicolumn{5}{|c|}{ Ethnicity } & \multicolumn{5}{|l|}{ Alarm type } \\
\hline & & & $M$ & $F$ & $\begin{array}{l}\text { Not } \\
\text { specified }\end{array}$ & White & Black & Bengali & Other & $\begin{array}{l}\text { Not } \\
\text { specified }\end{array}$ & $\begin{array}{l}\text { lonisation } \\
\text { zinc } \\
\text { battery }\end{array}$ & $\begin{array}{l}\text { lonisation } \\
\text { zinc battery } \\
\text { pause button }\end{array}$ & $\begin{array}{l}\text { lonisation } \\
\text { lithium battery } \\
\text { pause button }\end{array}$ & $\begin{array}{l}\text { Optical } \\
\text { lithium } \\
\text { battery }\end{array}$ & $\begin{array}{l}\text { Optical } \\
\text { zinc } \\
\text { battery }\end{array}$ \\
\hline $\begin{array}{l}\text { Working } \\
\text { people }\end{array}$ & 7 & 3 & 5 & 2 & 0 & 5 & 0 & 0 & 2 & 0 & 2 & 3 & 2 & & \\
\hline Older people & 19 & 3 & 7 & 12 & 0 & 17 & 1 & 0 & 1 & 0 & 8 & 5 & & 5 & 1 \\
\hline Parents & 6 & 2 & 2 & 4 & 0 & 4 & 2 & 0 & 0 & 0 & & 1 & 2 & 1 & 2 \\
\hline House bound & 3 & $\mathrm{~N} / \mathrm{A}$ & 1 & 2 & 0 & 2 & 1 & 0 & 0 & 0 & 2 & & & 1 & \\
\hline $\begin{array}{l}\text { Non-English } \\
\text { speakers }\end{array}$ & 6 & N/A & 1 & 5 & 0 & 0 & 0 & 5 & 1 & 0 & 1 & 1 & 2 & 1 & 1 \\
\hline Other & 7 & 2 & 2 & 5 & 0 & 5 & 2 & 0 & 0 & 0 & 1 & & 2 & & 4 \\
\hline $\begin{array}{l}\text { Intention to } \\
\text { treat }\end{array}$ & 10 & $\mathrm{~N} / \mathrm{A}$ & 3 & 7 & 0 & 6 & 2 & 0 & 0 & 2 & 3 & 0 & 1 & 2 & 2 \\
\hline Total adult & 58 & 10 & 21 & 137 & 0 & 39 & 8 & 5 & 4 & 2 & 16 & 12 & 10 & 10 & 10 \\
\hline Total children & 41 & 4 & - & - & 41 & - & - & - & - & 41 & $\mathrm{~N} / \mathrm{A}$ & & & & \\
\hline
\end{tabular}

frightened her so much, she started screaming at me. And I didn't know how to turn this thing off.

Mother, white (2)

Unfortunately with the alarm we have, I don't know what's wrong with it, but it's gone crazy. It just keeps going on and on... there was no smoke around at all, just something happened.

\section{Father, black}

The participants who reported these problems had all eventually disabled the alarm by taking out the batteries or taking it down from the ceiling.

The researchers received a number of telephone messages and a letter asking for help ("could you please send someone around after Wednesday 4 July"). The letter made clear the distress caused by the smoke alarm:

I'm sorry but it really stressed me out, what with the heat and climbing up ladders to try and stop it. ... It went off Wednesday after the cooking of dinner and despite fanning with towels and other things it just kept going. In desperation I put my electric fan on but it kept going on for an hour. There was no build up of smoke to start it off, just a slight cooking haze.

Letter from woman, over 65 years, white

\section{Problems with maintenance}

Difficulties were reported in silencing the alarm, and reaching the alarm, for instance to change the battery or press the "pause" or "test" button (a particular problem for elderly and disabled participants). Some participants found it difficult to release the cover of the alarm to change the battery. In some cases alarms were irreparably damaged, or knocked off the ceiling, in an attempt to stop the noise. The mother above whose 3 year old had been frightened by the alarm finished her story:

So I grabbed a broom and I thought, I've got to hit that thing up there. So I started banging it with the broom... and it broke and smashed around me and that was it, that was the end of the smoke alarm.

Mother, white
So I tell [the installers] you must be joking. Me change that battery! ... It's very high for me on my own ... I have a bad leg, and I'm a diabetic and I wouldn't like to do anything that is out of the way now ... It's a very bad story for anyone with a bad leg or old people to do that ...

Man, over 65 years, black

As a result of learning of these problems in early interviews, later participants were asked directly about testing their alarm regularly. Several were unclear about this, and three described using a flame or cigarette. Thirteen were unclear about how to recognise a low battery signal and six described confusion arising from this.

We weren't aware of [the low battery signal], so we took the battery off [to stop the bleeping], but last week somebody came round, they told us [what the bleeping was].

\section{Woman, Bangladeshi}

With the batteries running out, they make a noise and it goes on and on and you think it's the phone... I woke up one night and I thought 'What's that noise?' I could hear every two or three seconds 'beep, beep' and I thought 'What on earth's that?' I never thought of the smoke alarm at the time.

\section{Woman, over 65 years, white}

Few participants reported dusting their alarms to clean the sensor. Four participants indicated a feeling of unease about the device and their lack of ability to control it:

[I] didn't [test] it, [I'm] too scared to try.

Woman, over 65 years, ethnicity "other"

Over a quarter of participants described giving or receiving help to family or neighbours as a result of these type of problems, and others described using a broom or umbrella to reach the "pause" or "test" button.

\section{Alarm sensitivity}

Of the 48 adult recipients interviewed, a third felt that their alarm was very sensitive, and a large number of children 


\section{Key points}

- Although trial participants consider themselves to be at high risk for fires and would recommend smoke alarms to others, the distress caused by false alarms is a major barrier to use.

- Respondents' reports on the distress caused by false alarms suggests that people balance immediate and longer term risks to their health and wellbeing when they disable alarms.

reported that the alarm invariably sounds when someone is cooking:

When [I] cook steam comes out [and sets off the alarm].

Woman, Bangladeshi

If your parents are cooking something - mostly the smoke alarm goes on when a parent's cooking something.

Child, 10-11 years

The man next door, every time he grills just a bit of bacon... then it starts the alarm off.

Woman, over 65 years, white

In a Chinese family we always fry things and sometimes if I fry too much the alarm goes off warning me... even my little boy says, 'too much oil!'

Father, Chinese

When my mum cooks anything yeah, it makes a noise.

\section{Child 10-11 years}

Three participants (two in Bangladeshi households) described taking the battery out of the alarm to stop it sounding while they were cooking. Several children also suggested this as an option.

Three participants raised concerns about the disturbance that the sounding alarm could cause neighbours:

I worried about my neighbours. Opposite to me there's an old lady and she can't sleep much and sometimes she sleeps during the day and [the alarm] will bother her ...

Mother, white

\section{Alarms as nuisance}

Alarms going off when there was no fire resulted in their being ignored as a nuisance (much like car alarms), or disabled by removing the batteries or the alarm.

Residents, including children, no longer associated frequently sounding alarms with emergencies:

When the smoke alarm goes off, I have to turn up the television.

\section{Child, 8 years}

Sometimes it's a bit annoying, cos last time I was asleep and my mum was cooking something and then it went on and it was so loud I had to wake up.

\section{Child aged 10-11 years}

Older participants suggested that the alarms that frequently sounded would be ineffective, as no one would respond:

The alarm make noise. What are you going to do? People are working. People don't want to help, leaving people dying in their room...'

Man, over 65 years, ethnicity "other"

\section{DISCUSSION}

\section{Principal findings}

The reasons why some participants refused installation of alarms and others stopped use after installation-as well as the reasons why others continued use throughout the trialare important for this and future work. Levers to continued alarm use included early warning in the event of fire and an increased sense of security. Those who refused alarm installation said they already had one, or were concerned at receiving an intervention that entailed giving a stranger access to their homes. Those who received alarms but stopped use cited a range of adverse effects including problems with maintenance and alarm sensitivity, leading to nuisance alarms and stress. This provides an explanation for the low level of functioning smoke alarms 15 months after installation. $^{5}$ Although trial participants, including children (see fig 1) considered themselves at high risk for fires and would recommend smoke alarms to others, respondents' reports on the distress caused by false alarms, and problems with maintenance, suggest that by disabling alarms, people are making rational decisions about their immediate health and wellbeing. In a population already managing a range of health risks, a public health intervention that makes mealtimes more, rather than less, stressful, and where noise can threaten leisure or relationships with fellow occupants, alarms could pose a threat to immediate wellbeing.

\section{Strengths and weaknesses of the study}

The strengths of qualitative work in a trial context include its potential to draw on the expertise of users, improve trial recruitment, ${ }^{17}$ and the opportunity it offers to identify

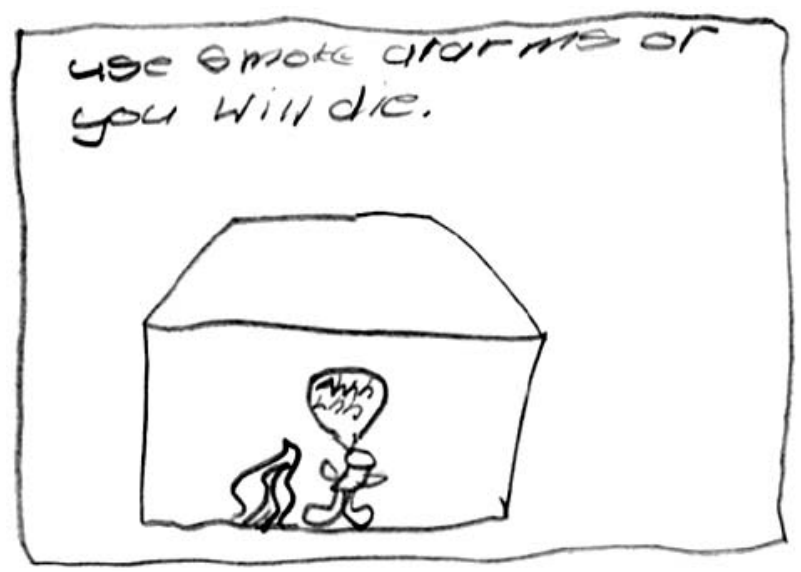

Figure 1 Example of a child's drawing. 


\section{Policy implications}

\section{For smoke alarm manufacturers}

- Many smoke alarms are disabled because of oversensitivity. Moreover changing the battery can be a problem and may entail hazardous manoeuvres, and maintenance instructions are frequently unclear. Improved design may lead to more consistent use.

\section{For regulatory authorities}

- Increasing incentives to manufacturers of smoke alarms to produce alarms that meet the needs of users should be considered.

\section{For researchers}

- Qualitative work is not a means of identifying how reluctant service users can be persuaded to accept interventions. Listening to end point users can help us identify problems and qualitative work embedded in a trial design can help identify levers and barriers to effective implementation.

\section{For funders}

- Encouraging research designs where different methods are appropriately staged may lead to better outcomes in real world implementation.

\section{For editors}

- Publishing the qualitative and trial results simultaneously can provide useful material for service planners and practitioners.

questions that are important to people receiving interventions. In this study the qualitative work followed trial recruitment. While a potential weakness includes bias introduced through the over-representation of "compliers" in the qualitative work, we were also able to recruit a sample of people who had been randomised but then withdrew before receiving a smoke alarm. Without research of this kind, false assumptions may be made about why some families forgo smoke alarms. After publication of the trial results in the $B M J,{ }^{5}$ one reader asked: "What is ... one to make of six pages devoted to the hardly surprising fact that feckless families do not bother to use smoke alarms." ${ }^{18}$ As our findings show, there is more to disabling smoke alarms than fecklessness.

\section{Implications of the study}

Policy development within and beyond medicine in the UK in the past decade has given increasing prominence to questions of effectiveness. ${ }^{19}$ A number of research initiatives, including the UK Economic and Social Research Council's Evidence Network $^{20}$ and the Campbell Collaboration ${ }^{21}$ - a "sister" to the Cochrane Collaboration, working on social care, education and criminal justice-have been established. Despite critiques from the social sciences of preventive activities ${ }^{22}$ and the notion that "prevention" should be exempt from critical scrutiny, ${ }^{92}$ the " $\mathrm{D}^{\prime \prime}$ aspect of the R\&D needed to underpin public health interventions remains undeveloped, and is an area where there are questions around implementation, relevance, cost effectiveness, and acceptability to those on the receiving end.

This work resonates with other studies in which health knowledge and health behaviours may be at odds. Studies of women smoking, for instance, have shown that they are well aware of the risks, but preventive or health promotion efforts may be ineffective so long as women experience short term health gains, such as creating a little space for themselves ("I'll be with you when I've had this cigarette"). ${ }^{22}$ Smoke alarms may be seen as a potential health benefit, but the stressful effect of an alarm going off in overcrowded or noisy accommodation may make them less than attractive interventions.

In a successful implementation programme, effective maintenance support, as well as installation of the alarm type found in the trial to be the most likely to be working after 15 months may be associated with higher rates of smoke alarm functioning. Manufacturers may need to explore other ways of ensuring that smoke alarm users can feel in better control of the alarms in their home.

\section{Unanswered questions and future research}

While the findings of the trial ${ }^{5}$ suggest a clear "best buy" in terms of the battery operated smoke alarm most likely to be functioning 15 months after installation in this population, the comparatively low levels of functioning indicate that there is a good deal more to be done in finding acceptable smoke alarms, and addressing a health risk with important implications for reducing inequalities.

Developing appropriate methodologies linking trial and qualitative work may lead to better outcomes in real world implementation. ${ }^{24}$ Further work also needs to be done on methodological triage. ${ }^{25}$ It may well be that a more appropriate design would have started with qualitative work, improving take up and maintenance instructions.

\section{ACKNOWLEDGEMENTS}

Those living on the council estate and the children at its local primary school are in a sense co-authors of this work, and we thank them, and the staff of the primary school, for their help. Jo Dearlove, Anna Downie, and Catherine Godward assisted with data collection from children. Angela Wade, Mark Sculpher, and Maggie Barker made helpful observations in the course of the study design and subsequently. We are grateful to the three peer reviewers who looked at this paper, Danny Dorling, Ian Graham, and an unnamed referee for their useful comments.

\section{Authors' affiliations}

H Roberts, K Curtis, K Liabo, Child Health Research and Policy Unit, City University, London, UK

D Rowland, I Roberts, Public Health Intervention Research Unit, Department of Epidemiology and Population Health, London School of Hygiene and Tropical Medicine, London, UK

C DiGuiseppi, Department of Preventive Medicine and Biometrics, University of Colorado Health Sciences Center, USA

Funding: The UK Medical Research Council (ISRCTN 47572799); Camden and Islington Health Action Zone, the West Euston Partnership; and the Joan Dawkins Fund

Conflicts of interest: none declared.

\section{REFERENCES}

1 National Statistics. Britain update: November 2000. London: National Statistics, 2000

2 DiGuiseppi C, Roberts I, Speirs N. Smoke alarm installation and function in inner London council housing. Arch Dis Child 1999;81:400-3.

3 Arai L, Popay J, Roberts H, et al. Preventing accidents in children - how can we improve our understanding of what really works? Exploring methodological and practical issues in the systematic review of factors affecting the implementation of child injury prevention initiatives. Final report to the Health Development Agency. London: City University and Lancaster University, 2003.

4 Marriott MD. Reliability and effectiveness of domestic smoke alarms (research report 58). London: Home Office Fire Research and Development Group, 1994.

5 Rowland D, DiGiuseppi C, Roberts I, et al. Increasing the prevalence of working smoke alarms in disadvantaged inner city housing: a randomised controlled trial. BMJ 2002;325:998-1001.

6 DiGuiseppi C, Roberts I. Individual-level injury prevention strategies in the clinical setting. Future Child 2000;10:53-82. 
7 Pless B. Smoke detectors and house fires; alarms failed because detectors were not installed or maintained properly. BMJ 2002;325:979-80.

8 Freeman R. The idea of prevention: a critical review. In: Scott S, ed. Private risks and public danger. Ashgate: Avery, 1992.

9 Roberts H, Smith S, Bryce C. Prevention is better... Sociology of Health and Illness 1993; 15:447-63

10 Rychetnick L, Frommer $M$, Hawe $P$, et al. Criteria for evaluating evidence on public health interventions. J Epidemiol Community Health 2002:56: 119-27.

11 Budd T, Mayhew P. Fires in the home in 1995: Results from the British Crime Survey (Issue 9/97). London: Government Statistical Service, 1997.

12 Roberts I, Power C. Does the decline in child injury mortality vary by social class? A comparison of class specific mortality in 1981 and 1991. BM 1993;313:784-6.

13 Roberts I. Cause specific social class mortality differentials for child injury and poisoning in England and Wales. J Epidemiol Community Health 1997:51:334-5.

14 Popay J, Williams G. Qualitative research and evidence based healthcare. J R Soc Med 1998;91(suppl 35).

15 Glaser B, Strauss A. The discovery of grounded theory: strategies for qualitative research. Chicago: Aldine, 1967.
16 DiGuiseppi C, Roberts I, Li L, et al. Determinants of car travel on daily journeys to school: cross sectional survey of primary school children. BM 1998;316:1426-8.

17 Donovan J, Mills N, Smith M, et al. Improving design and conduct of randomised trials by embedding them in qualitative research: ProtecT (prostate testing for cancer and treatment) study. BMJ 2002;325:766-70.

18 Hill GG. Smoke alarms [electronic response to Pless B. Smoke detectors and house fires]. BMJ 2002. http://bmi.com/cgi/eletters/325/7371/ 979\#26666 (accessed Jun 2003).

19 Davies HTO, Nutley SM, Smith PC. What works? Evidence-based policy and practice in public services. Bristol: Policy Press, 2000.

20 Evidence network. http://www.evidencenetwork.org (accessed Jun 2003)

21 Campbell Collaboration. http://www.campbellcollaboration.org (accessed Jun 2003).

22 Graham H. When life's a drag: women, smoking and disadvantage. London: HMSO, 1993.

23 Scrabanek $\mathbf{P}$. Why is preventive medicine exempted from ethical constraints ? J Med Ethics 1990;16:187-90.

24 Roberts H. Qualitative methods in intervention in injury. Arch Dis Child 1997:76:487-9.

25 Petticrew M, Roberts H. Evidence, hierarchies and typologies: horses for courses. J Epidemiol Community Health 2003;57:527-9.

\section{THE JECH GALLERY}

Influential women in occupational health Yiqun Wu-The Chemistry of Preventive Medicine

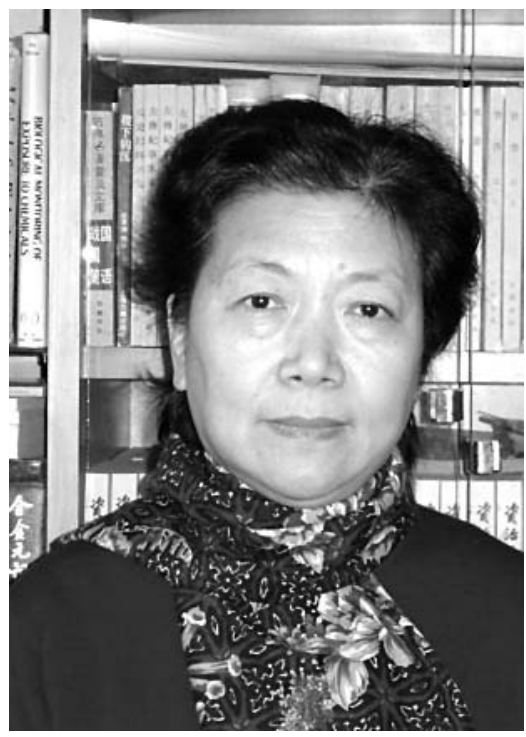

May 1946-

Country of birth: People's Republic of China

rofessor Yiqun Wu is a key figure in the prevention of lead poisoning, a problem of epidemic proportion in China. She proposed a national prevention strategy for childhood lead poisoning to the government, including training courses, and publication of educational materials. "Our problem is similar to the conditions Alice Hamilton described in Chicago over 80 years ago."

With China's political and economic changes are concomitant health risks associated with developing nations, as well as lifestyle disease and risks from industrial pollution and imported waste.

$\mathrm{Wu}$ established the first national poison control centre in China, and directed the biological monitoring programme with a network of 125 provincial laboratories. As a chemist, she validated biological exposure indicators for several chemical compounds.

"China has many environmental problems accompanying industrialization, but the release of environmental lead may well be the worst problem we have yet faced."

She helped launch an AIDS Prevention Project between China and Britain. More than one million HIV cases are estimated in 31 Chinese provinces and autonomous regions.

She is now Executive Deputy Director of China's private, non-profit ThinkTank Research Center for Health Development, working with Chen Chunming. Wu also serves as Vice President of the Chinese Academy of Preventive Medicine.

D F Salerno Clinical Communications Scientist, Pfizer Global Research and Development, Ann Arbor Laboratories, Ann Arbor, MI, USA

I L Feitshans

Adjunct Faculty, Cornell University, School of Industrial and Labor Relations, Albany, NY, USA

Correspondence to: Deborah F Salerno, 2800 Plymouth Road, Ann Arbor, MI 48105, USA; deborah.salerno@pfizer.com 